\title{
Mechanical properties of sunflower oil under pressure
}

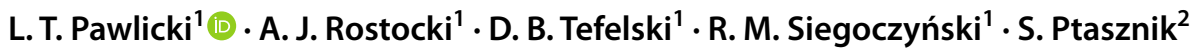

Received: 17 July 2021 / Revised: 18 September 2021 / Accepted: 2 October 2021 / Published online: 15 November 2021 (c) The Author(s) 2021

\begin{abstract}
This article presents the results of research on the influence of high pressure on the mechanical properties of sunflower oil. The pressure value was changed by the stepwise method to obtain thermodynamic equilibrium. Dependencies of changes in the volume and compressibility of sunflower oil on pressure were investigated. A discontinuous (step) change was observed indicating the appearance of the first order phase transformation. The phase transition for sunflower oil was observed in the pressure range from 450 to $500 \mathrm{MPa}$ after about $170 \mathrm{~h}$. Most likely, then, there was a change to the double crystal phase. The time after which this transformation took place was the longest of all times that the authors have observed so far for the study.
\end{abstract}

Keywords Sunflower oil $\cdot$ High pressure $\cdot$ Compressibility $\cdot$ Phase transition

\section{Introduction}

The development of high pressure food preservation (HPP) methods in many laboratories around the world has initiated, the intensive research into changes in the physical properties of edible oils under the influence of high pressure. In this method (HPP), food is stored for 5-20 min in a pressure chamber under a pressure of about $600 \mathrm{MPa}$ [1-6]. The effect of pressure on the properties of edible oils is of interest as they are one of the main ingredients in high pressure preserved foods. On the other hand, phase transitions caused by high pressure occur in vegetable oils and then require a fairly long keeping of the oil under high pressure above a certain minimum pressure value characteristic for each type of oil. This time can be up to several hundred hours. For the first time such a transformation was observed in the case of castor oil [7]. Transitions caused by the increase in pressure are analogous to the changes caused by lowering the temperature and constitute a transition to a crystalline or amorphous solid state. Phase transitions caused by temperature changes in oils have been known for quite a long time [8-12]

$\triangle$ L. T. Pawlicki

leszek.pawlicki@pw.edu.pl

1 Faculty of Physics, Warsaw University of Technology, ul. Koszykowa 75, 00-662, Warsaw, Poland

2 Department of Fat and Meat Technology, Institute of Agricultural and Food Biotechnology, ul. Jubilerska 4, 04-190 Warsaw, Poland while the influence of pressure was mainly reduced to the study of PVT characteristics [13, 14]. Recently, the significant progress has been made $[15,16]$ by the optical observation of pressure-induced crystallization of triglycerides. The properties of edible oils were also tested in the high pressure laboratories. These experiments were a continuation of previous studies on pressure changes of the physical properties of castor oil [17]. The measurements of optical properties of triglycerides [18] showed the occurrence of the first order phase transformations. This phenomenon in the formation of a pressure-induced phase transition has been investigated with multiple methods, showing discontinuous changes in volume [19], refractive index [18], dielectric permittivity [20] and viscosity [21-23] during the phase transition. Most of these effects have been summarized in the paper [17]. Further, progress was achieved thanks to the study of pressure changes of triolein [14, 22, 24, 25] showing similar phase transformations as in castor oil. Both these substances are the mixtures of fatty acids triglycerides. On this basis, the authors predicted the occurrence of a phase change in a wide class of edible oils with the above properties [26-28]. These predictions were confirmed by observations of the phase change in rapeseed oil [26]. Further, the measurements of the $V(p)$ and $\varepsilon(p)$ dependences were performed for soybean oil [27] and lately in olive oil [28], showing a similar behavior. Therefore, it is expected that sunflower oil should have a similar relationship between volume and pressure. So the authors have tested sunflower oil under high pressure. All the described oils are mixtures of triglycerides, 
which causes phase transitions between the liquid phase and the alpha, triple and double crystal forms [29].

\section{Experimental arrangement}

Sunflower oil produced by A.C.E.F. Spa (Italy) was used for the experiments. The molecular composition of the sunflower oil which was used in this research is presented in Table 1.

As it can be seen in Table 1 the sunflower oil is a molecular mixture mainly of triglycerides of linoleic acid $(57.0 \%)$ and oleic acid $(30.7 \%)$. The physical properties of sunflower oil with high oleic acid content were described in [30-32]. It was all the more interesting to compare the pressure transitions from this publication with the changes

Table 1 Sunflower oil molecular composition

\begin{tabular}{lll}
\hline Fatty acids & \multicolumn{2}{c}{$\%$} \\
\hline Miristic acid & C14:0 & 0.08 \\
Palmitic acid & C16:0 & 6.8 \\
Palmitoleic acid & C16:1 & 0.1 \\
Margaric acid & C17:0 & 0.05 \\
Margaroleic acid & C17:1 & 0.05 \\
Stearic acid & C18:0 & 4.0 \\
Oleic acid & C18:1 & 30.7 \\
Linoleic acid & C18:2 & 57.0 \\
$\alpha$-linolenic acid & C18:3 & 0.1 \\
Arachidic acid & C20:0 & 0.3 \\
\hline
\end{tabular}

observed by the authors of this article, and also whether there is no phase transition at a slightly higher pressure, which was not shown in the work [31].

The experimental setup used in our research is shown in Fig. 1.

The samples were placed under high pressure in the chamber (1) in the form of a thick-walled cylinder with an internal diameter of $17 \mathrm{~mm}$ with a straight piston [26]. The force on the piston was exerted by means of a hydraulic press with a pressure of up to 20 tons (2). All this mechanical system was connected with the electronic system, which consisted of a set of electronic meters and a multi-channel data acquisition system operating in the LAB VIEW environment by National Instruments. The maximum pressure has been limited to about $1.2 \mathrm{GPa}$ due to the maximum pressure of the hydraulic press (2). The displacement of the piston was measured using an electronic caliper (7) with a resolution of $0.01 \mathrm{~mm}$ which was also connected to the data acquisition system via the RS232 interface (8). A manganine transducer with a resistance of $500 \Omega$ was used to measure the pressure. The resistance of this transducer was measured with a precision HP 34,970 multimeter (5). The pressure measurement resolution was better than $\pm 0.5 \mathrm{MPa}$. The sensor was calibrated using a MT 6000 weight and piston pressure gauge having class 0.05 .

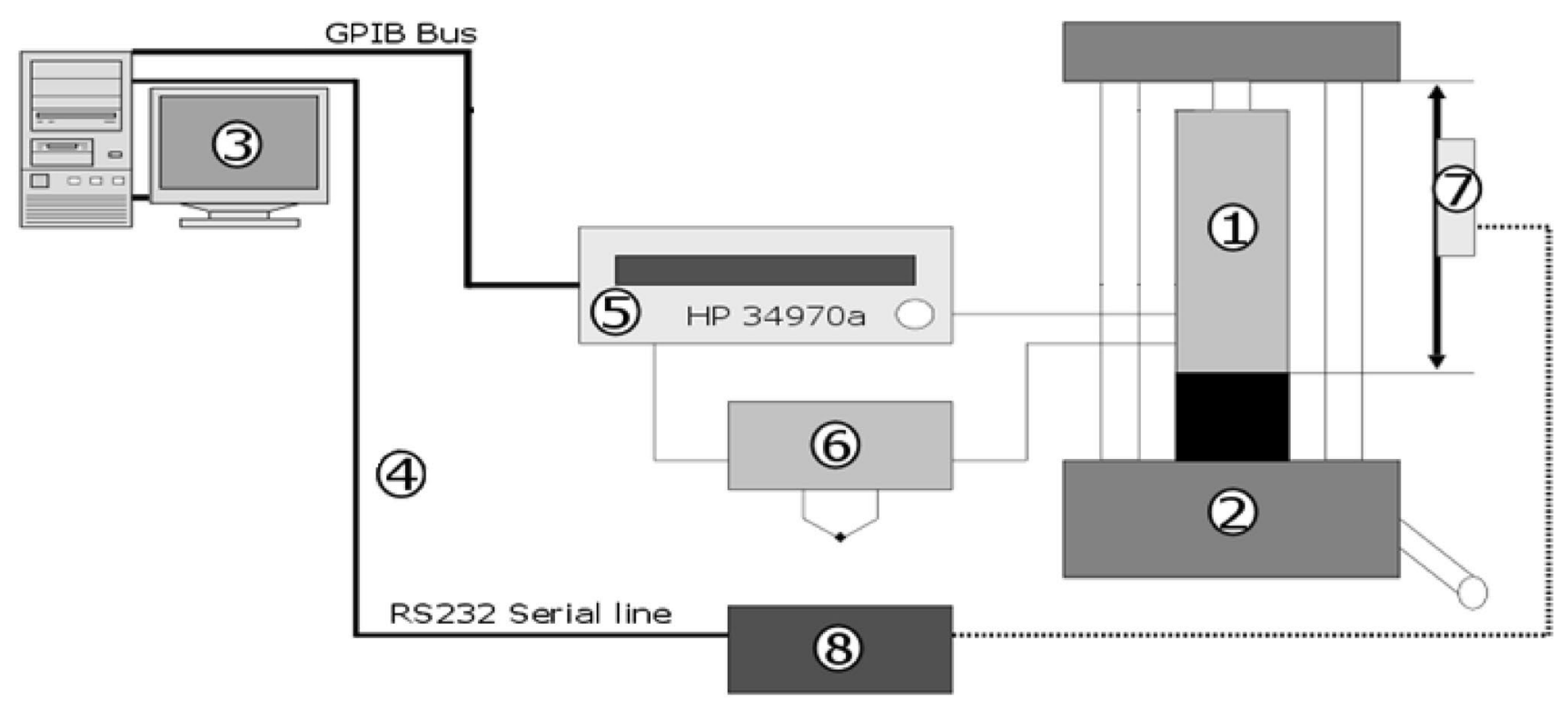

Fig. 1 Data acquisition system. 1-high pressure chamber, 2hydraulic press, 3 - computer with LabVIEW based acquisition system, 4-RS232 line, 5-multimeter with multiplexer, 6- thermocou- ple with temperature reference system, 7-digital calliper, 8-RS232 interface for digital calliper 


\section{Results of the measurement}

The pressure was generated by a hand pump in steps of $40 \mathrm{MPa}$ and then held constant for approximately $2 \mathrm{~min}$. To make sure that the occurring changes result from the examined phenomenon and not from the random changes of individual parameters, changes of all measured values as a function of time were observed simultaneously in individual windows on a common screen. This allowed the pressure drop to be distinguished resulting from a first order phase transition from ordinary leakage. It also allowed the system to achieve the thermodynamic equilibrium. During this time, the temperature, which was increasing due to the stepwise compression of the oil, could return to its original value and the system reached the thermodynamic equilibrium.

\section{$p-V$ dependence}

On the basis of $p(t)$ dependence and $V(t)$ dependence, the $V(p)$ dependence was calculated and presented in Fig. 2. For the analysis of results, the modified Tait equation [33-35] was adopted in the form of:

$\frac{V}{V_{0}}=1-C \ln \left(1+\frac{p}{B}\right)$

where $V$ is the volume of oil, $V_{0}$ is the initial volume of oil, $\mathrm{p}$ is pressure, $C$ and $B$ are fitting factors. The Tait equation curve fitting was done using the Levenberg-Marquard optimization method. The obtained fitting coefficients were: $C=0.079, B=0.077 \mathrm{GPa}$. On this basis, the isothermal compressibility can be calculated from the following expression:

$\beta_{T}(p, V)=\frac{-1}{V}\left(\frac{\partial V}{\partial p}\right)_{T}$

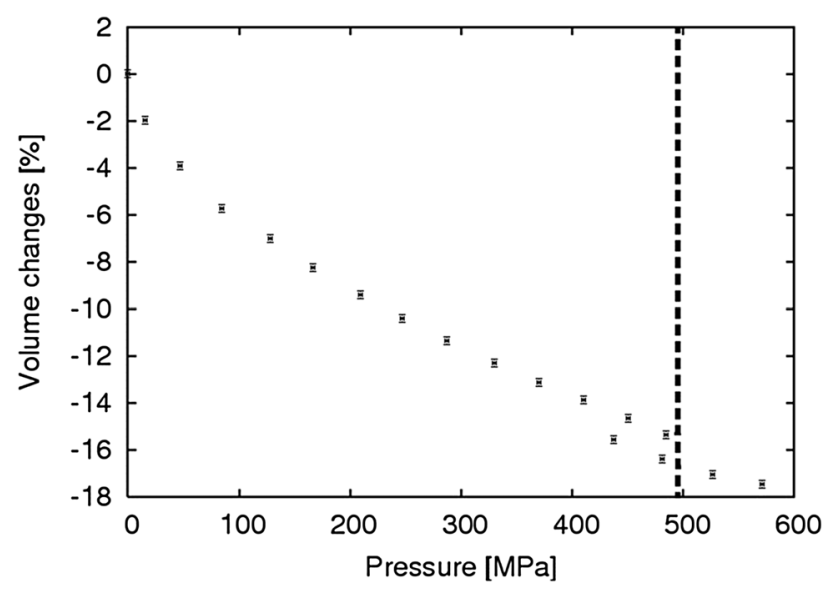

Fig. 2 Volume change as a function of pressure of sunflower oil
By differentiating the Tait equation we can get an expression enabling to calculate the compressibility of the compress liquid:

$\beta_{T}(p, V)=\frac{C \cdot V_{0}}{V(p+B)}$

The above relationship between $p$ and $V$ and the respective values of the $C$ and $B$ coefficients was correct in the range of pressures lower than the phase transition pressure. In Fig. 2, each of the steps in Fig. 3 is marked with a corresponding point. At a pressure of about $0.47 \mathrm{GPa}$, a sharp drop in volume can be seen as the oil solidifies. Above this point, the relation $V(p)$ is similar, but slightly shifted downwards. In this range, the changes in volume depended not only on pressure but also on time, which suggests the coexistence of two phases and the ongoing phase transition process. In other words, the pressure was decreasing for about $2-3 \mathrm{~h}$ after repositioning the piston (no oil leakage was observed). This means that during this time some of the oil changed its structure to the new one with much smaller volume (higher density) probably double. The results of the first part correspond very well with the results presented by Guignon [31]. Above the phase transition, the pressure range was too short to find the matching factors for the next phase of sunflower oil.

The PVT dependence can also be determined alternatively on the basis of the free-volume theory $[36,37]$.

\section{Discussion}

It is clear, that a phase transitions was observed for the sunflower oil. This transformation is very similar to the one previously found in castor, rapeseed [26] and soybean oils [27]. Both the pressure range and the direction of changes (rapid volume decrease) are similar to the changes observed in castor oil [21, 22]. The difference appeared in the form of the dynamics of the phase transition and the relaxation time. The phase transition time was longer than in other oils. Although the optical properties have not been tested under pressure, in the oil removed from the high pressure chamber after the end of the experiment the abnormal lateral scattering of the laser beam transmitted through this oil was observed. This phenomenon lasted for about 2-3 days and then it gradually disappeared. A similar phenomenon was previously observed in rapeseed oil. The phase transformation presented in this paper should be further investigated using other pressure methods. It seems that it is very important for the food preservation process because the pressure of this transformation is in the range of HPP technology working pressures. 


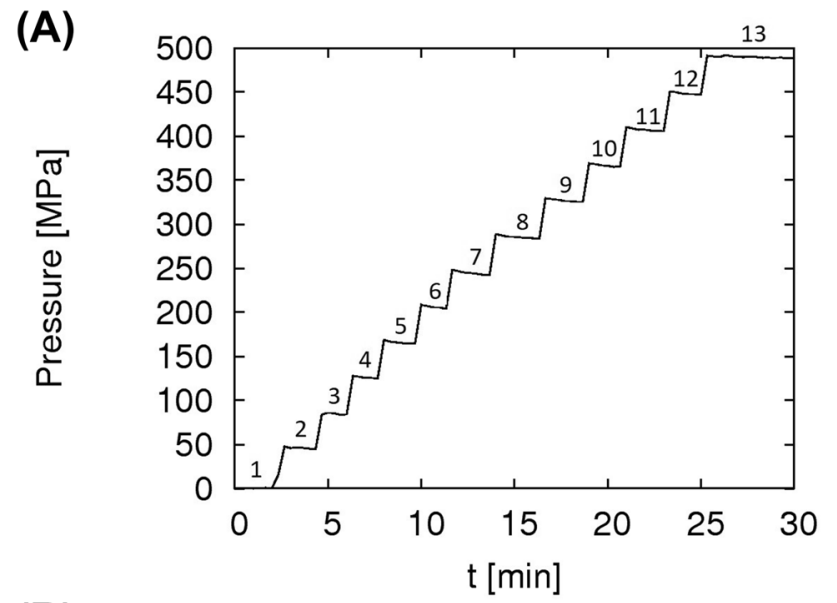

provide a link to the Creative Commons licence, and indicate if changes were made. The images or other third party material in this article are included in the article's Creative Commons licence, unless indicated otherwise in a credit line to the material. If material is not included in the article's Creative Commons licence and your intended use is not permitted by statutory regulation or exceeds the permitted use, you will need to obtain permission directly from the copyright holder. To view a copy of this licence, visit http://creativecommons.org/licenses/by/4.0/.
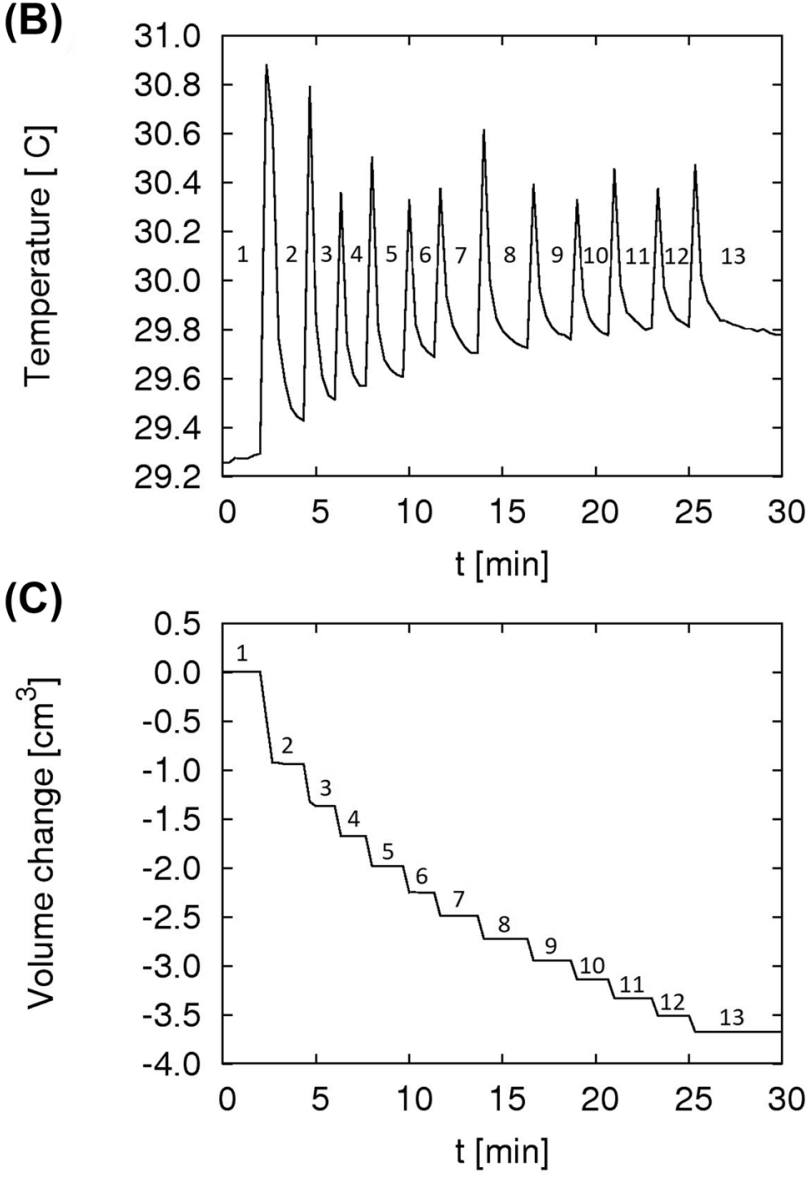

Fig. 3 The simultaneous run of the 5 measuring channels of the acquisition system. A Pressure in the chamber, $\mathbf{B}$ the temperature inside chamber, $\mathbf{C}$ volume change

\section{Declarations}

Conflict of interest We do not have any conflicts of interest.

Open Access This article is licensed under a Creative Commons Attribution 4.0 International License, which permits use, sharing, adaptation, distribution and reproduction in any medium or format, as long as you give appropriate credit to the original author(s) and the source,

\section{References}

1. Knorr D (1993) Effects of high-hydrostatic-pressure processes on food safety and quality. Food Technol 47(6):156-161

2. Torres JA, Velásquez G (2005) Commercial opportunities and research challenges in the high pressure processing of foods. J Food Eng 67:95-112

3. Norton T, Da-Wen S (2008) Recent advances in the use of high pressure as an effective processing technique in the food industry. Food Bioproc Technol 1:2-34

4. Tonello C (2010) Case studies on high-pressure processing of foods. Nonthermal processing technologies for food. Wiley-Blackwell, Oxford, pp 36-50

5. Jung S, Tonello-Samson C (2011) High hydrostatic pressure food processing: potential and limitations. In: Proctor A (ed) Alternatives to conventional food processing. RSC Publishing, London, pp 254-305

6. Balasubramaniam VM, Barbosa-Canovas GV, Lelieveld H (2016) High pressure processing of food-principles, technology and application. Springer, New York

7. Siegoczyński RM, Jędrzejewski J, Wiśniewski R (1989) Long time relaxation effect of liquid castor oil under high pressure condition. High Press Res 1:225-301

8. Ferguson RH, Lutton ES (1947) The polymorphism of triolein. J Am Chem Soc 69(6):1445-1448

9. Akita C, Kawaguchi T, Kaneko F (2006) Structural study on polymorphism of cis-unsaturated triacylglycerol: Triolein. J Phys Chem B 110:4346-4353

10. Hollander FF, Boerrigter SXM, van de Streek J, Bennema P, Meekes H, Yano J, Sato K (2003) Comparing the morphology of $\beta$-n.n.n. with $\beta$ '-n.n+2.n and $\beta$ ' n.n.n-2 triacylglycerol crystals. J Phys Chem B 107:5680-5689

11. Sato K (1999) Solidification and phase transformation behaviour of food fats-a review. Fett/Lipid 101(12):467-474

12. Sato K (2001) Crystallization behaviour of fats and lipids-a review. Chem Eng Sci 56:2255-2265

13. Rostocki AJ, Tefelski DB, Ptasznik S (2009) Compressibility studies of some vegetable oils up to $1 \mathrm{GPa}$. High Press Res 29(4):721-725

14 Rostocki AJ, Tefelski DB, Wieja K (2011) The equation of state of triolein up to 1GPa. High Press Res 31(1):168-171

15. Ferstl P, Gillig S, Kaufmann C, Dürr C, Eder C, Wierschem A, Ruß W (2010) Pressure induced phase transitions in triacylglycerids. Ann NY Acad Sci 1189:62-67

16 Ferstl P, Eder C, Ruß W, Wierschem A (2011) Pressureinduced crystallization of triacylglycerides. High Press Res 31(2):339-349

17. Siegoczyński RM (1998) Reports of the Institute of Physics, Publishing House of the Warsaw University of Technology. Warsaw University of Technology, Warsaw

18. Siegoczyński RM, Jędrzejewski J, Wiśniewski R (1991) The influence of pressure on the refractive index of castor oil up to $0.8 \mathrm{GPa}$. High Press Res 8:439-441 
19. Wiśniewski R, Jędrzejewski J, Siegoczyński RM, Tkacz A (1994) Volume changes of castor oil during its transformation to the high pressure phase. High Press Res 11:385-391

20. Wiśniewski R, Jędrzejewski J, Siegoczyński RM (1994) Dielectric permittivity and dielectric loss of castor oil during its transformation to the high pressure phase. High Press Res 13:41-45

21. Wiśniewski R, Siegoczyński RM, Rostocki AJ (2005) Viscosity measurement of some castor oil based mixtures under high pressure conditions. High Press Res 25:63-70

22. Siegoczyński RM, Rostocki AJ, Kiełczyński P, Szalewski M (2008) A viscosity measurement during the high pressure phase transition in triolein. J Phys Conf Ser 121:142010

23. Rostocki AJ, Siegoczyński RM, Kieczyński P, Szalewski M (2010) An application of love SH waves for the viscosity measurement of triglycerides at high pressures. High Press Res 30(1):88-92

24. Tefelski DB, Jastrzębski C, Wierzbicki M, Siegoczyński RM, Rostocki AJ, Wieja K, Kościesza R (2010) Raman spectroscopy of triolein under high pressures. High Press Res 30:124-129

25. Kos A, Tefelski DB, Kościesza R, Rostocki AJ, Roszkiewicz A, Ejchart W, Jastrzębski C, Siegoczyński RM (2007) Certain physico-chemical properties of triolein and methyl alcohol- triolein mixture under pressure. High Press Res 27:39-42

26. Rostocki AJ, Wiśniewski R, Wilczyńska T (2007) High pressure phase transition in rapeseed oil. J Mol Liq 135:120-122

27. Rostocki AJ, Kościesza R, Tefelski DB, Kos A, Siegoczyński RM, Chruściński Ł (2007) Pressure induced phase transition in soy oil. High Press Res 27:43-46

28. Pawlicki LT, Siegoczyński RM, Ptasznik S, Marszałek K (2021) Electric properties of olive oil under pressure. Eur Food Res Technol 247(8):1933-1937

29. Zulkurnain M, Maleky F, Balasubramaniam VM (2016) High pressure processing effects on lipids thermophysical properties and crystallization kinetics. Food Eng Rev 8:393-413
30. Guinda Á, Dobarganes MC, Ruiz-Mendez MV, Mancha M (2003) Chemical and physical properties of a sunflower oil with high levels of oleic and palmitic acids. Eur J Lipid Sci Technol 105:130-137

31. Guignon B, Aparicio C, Sanz PD (2009) Volumetric properties of sunflower and olive oils at temperatures between 15 and $55^{\circ} \mathrm{C}$ under pressures up to $350 \mathrm{MPa}$. High Press Res 29:38-45

32. Cardenia V, Rodriguez-Estrada MT, Cumella F, Sardi L, Della CG, Lercker G (2011) Oxidative stability of pork meat lipids as related to high-oleic sunflower oil and vitamin E diet supplementation and storage conditions. Meat Sci 88:271-279

33. Neece GA, Squire DR (1968) On the Tait and related empirical equations of state. J Phys Chem 72:128-136

34. Malhotra R, Woolf LA (1991) Extrapolation of (p, V, T) data for liquids. High Temp High Press 23:107-110

35 Kumagai A, Iwasaki H (1979) Pressure-volume-temperature relationships of $\mathrm{CH} 3 \mathrm{COOC} 2 \mathrm{H}$, and generalized tait equation for liquids at high pressures. J Chem Eng Data 24(4):261

36. Oversteegen SM, Roth R (2005) General methods for free-volume theory. J Chem Phys 122:214502-1-214512

37. Arakawa K, Kojima K (1975) Investigation of the concept of free volume by means of a correlation function method. Bull Chem Soc Jpn 48:26-28

Publisher's Note Springer Nature remains neutral with regard to jurisdictional claims in published maps and institutional affiliations. 